\title{
Excretion of 5-hydroxyindolyl acetic acid (5HIAA) in migraine
}

\author{
G. CURZON, PRUNELlA THEAKER, AND B. PHILlipS
}

From the Department of Chemical Pathology, Institute of Neurology, The National Hospital, London

During the prodromal phase of a migraine attack, vasoconstriction occurs which is followed during headache by the dilatation of cranial blood vessels (Marcussen and Wolff, 1950). Therefore, the metabolism in migraine of physiologically occurring vasoactive substances such as 5-hydroxytryptamine (5HT) and the catecholamines is of interest. $A$ further indication of the possible importance of 5HT is that ergot alkaloids, such as methysergide, used in the treatment of migraine are pharmacological antagonists of this substance. In particular, Sicuteri, Fanciullacci, Del Bianco, and Franchi (1964) find that methysergide prevents the venoconstrictive effect of 5HT. Sicuteri, Testi, and Anselmi (1961) have reported elevated 24-hour excretion of 5HIAA (the main urinary metabolite of 5HT) by some migraine patients on the days during which attacks occurred. Excretion of 3-methoxy-4-hydroxymandelic acid (V.M.A.), the main urinary metabolite of noradrenaline and adrenaline, has also been claimed by Sicuteri (1963) to be raised during attacks.

Because of these observations, it was thought worthwhile to investigate 5HIAA excretion in migraine in greater detail, paying particular attention to the control of extraneous factors known to $\checkmark$ affect excretion of this substance. The excretions by some of the patients of another tryptophan metabolite, indoxyl sulphate, and of V.M.A. were also measured.

\section{MATERIALS}

PATIENTS The 13 patients studied in the main series of experiments included nine migraine subjects and four controls. The migraine subjects were subject to frequent attacks and admitted to hospital specifically for this reason, there being no evidence of any other organic disease. The control subjects were patients in a neurological hospital without demonstrable organic neurological disease or vascular or gastrointestinal disease. The patients cooperated actively in the study and filled in daily charts giving chronological and symptomatic details of their headaches. All patients were ambulant.

Except where specifically stated otherwise, the normal hospital diet was used except that the following foods, which are known to contain 5HT in considerable amount, were excluded from the diet: bananas (Waalkes, Sjoerdsma, Creveling, Weissbach, and Udenfriend, 1958), pineapple (Bruce, 1960), walnuts (Kirberger and Braun, 1961), grapefruit and apricots (West, 1958). Alcohol was not allowed as it has been reported by Rosenfeld (1960) to influence SHIAA excretion. Patients were taken off all drugs three days before the start of investigations. The daily fluid intake of each subject was controlled to a fixed volume.

URINE COLLECTIONS Urine specimens were collected over four-hour periods for a varying number of days. Each specimen was collected into $1 \mathrm{ml}$. of $6 \mathrm{~N} \mathrm{HCl}$, and on completion, placed in a cold room at $4^{\circ} \mathrm{C}$. After measurement of volume, $50-100 \mathrm{ml}$. samples were stored at $-25^{\circ} \mathrm{C}$. until determinations were made.

\section{METHODS}

5HIAA An 1/80 sample of each four-hourly urine specimen was brought to $9 \mathrm{ml}$. with water and used for each determination, thus avoiding the possibility of error due to low recoveries from concentrated urines. (This precaution is of particular importance in the study of migrainous subjects who frequently show diuresis during attacks.) One $\mathrm{ml}$. of $6 \mathrm{~N}$ hydrochloric acid was added and 5HIAA determined essentially as Todrick, Dick, and Tait (1958), except that extinction was read at $540 \mathrm{~m} \mu$ and a $4 \mathrm{~cm}$. light path was used. Recoveries of $15 \mu \mathrm{g}$. of 5HIAA added to a total of six urine samples from four subjects varied between 90 and $98 \%$. Certain drug metabolites may give colours with this method which are similar but not spectrally identical to that obtained from 5HIAA. Therefore, when urine specimens apparently contained high amounts of 5HIAA this was confirmed by determining the absorption spectrum. To confirm further the elevated excretion of 5HIAA, the acidified urine was saturated with $\mathrm{NaCl}$ and then extracted with ether, the extract evaporated to dryness under nitrogen, taken up in ethanol and 5HIAA demonstrated chromatographically by the method of Jepson (1955).

INDOXYL SULPHATE The method of Curzon and Walsh (1962) was used. Samples of 1/100 of each fourhourly urine specimen were brought to $1.0 \mathrm{ml}$. for determination. 
V.M.A. Samples, 3/500 of each four-hourly urine specimen, were brought to $2.5 \mathrm{ml}$. and V.M.A. determined (Pisano, Crout, and Abraham, 1962), correcting for p-hydroxymandelic acid as described by Pisano, Oates, Karmen, Sjoerdsma, and Udenfriend (1961).

CREATININE Metabolites were expressed in terms of creatinine excretion, thus correcting for possible defects in urine collection and minimizing the effect of variations in urine flow and the Morgenzacken effect described by Degkwitz, Frowein, Kirberger, Kulenkampff, and Mohs (1962). Creatinine was determined by the method of King and Wootton (1964).

\section{RESULTS}

Table I shows the mean four-hour excretion of 5HIAA/creatinine by migrainous and control subjects over some days. None of the migraine subjects consistently excreted grossly high amounts of

TABLE I

URINARY EXCRETION OF 5HIAA BY MIGRAINOUS AND CONTROL SUBJECTS

$\begin{array}{lll}\text { Subject } & \begin{array}{l}\text { No. of Four-hour } \\ \text { Specimens }\end{array} & \begin{array}{l}\text { Mean } \\ \text { 5HIAA/Creatinine } \\ (\text { mg./g. })\end{array}\end{array}$

S.D.

\begin{tabular}{lrr}
\hline Migraine & & \\
B.W. & 10 & $3 \cdot 01$ \\
F.R. & 32 & $3 \cdot 70$ \\
H.R. & 54 & $3 \cdot 07$ \\
I.B. & 11 & $1 \cdot 87$ \\
I.T. & 9 & $2 \cdot 07$ \\
M.C. & 38 & $3 \cdot 87$ \\
Mc. & 17 & $3 \cdot 19$ \\
M.Cr. & 48 & $4 \cdot 28$ \\
W. & 31 & $3 \cdot 23$ \\
Control & & \\
A.B. & 15 & $2 \cdot 42$ \\
A.P. & 14 & $2 \cdot 64$ \\
J.J. & 36 & $3 \cdot 26$ \\
S. & 6 & $2 \cdot 28$
\end{tabular}

5HIAA throughout the period of investigation. However, the three highest excretors were all in the migraine group and two of these, F.R. and M.Cr., showed the highest variability of excretion of all subjects investigated. Figure 1 shows in detail the variation with time of 5HIAA/creatinine excretion of two of the control subjects. Figure 2 shows the variation with time of the 5HIAA/creatinine and V.M.A./creatinine excretion of the migraine subject H.R. No significant relationship with headache periods is apparent. Neither is there any significant difference between the 5HIAA pattern and those of the control subjects shown in Figure 1. There is some suggestion of slightly higher 5HIAA/creatinine excretion during the night than during the day.

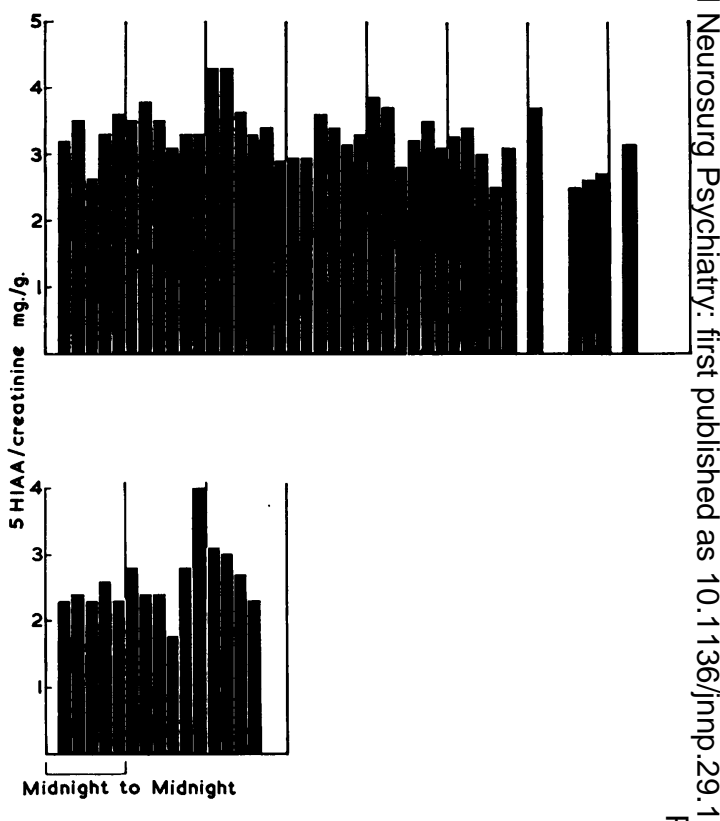

FIG. 1. Serial four-hourly urinary excretion of 5HIA34 creatinine by two control subjects. Above, J.J. Below, $A \Phi^{B} \circ$

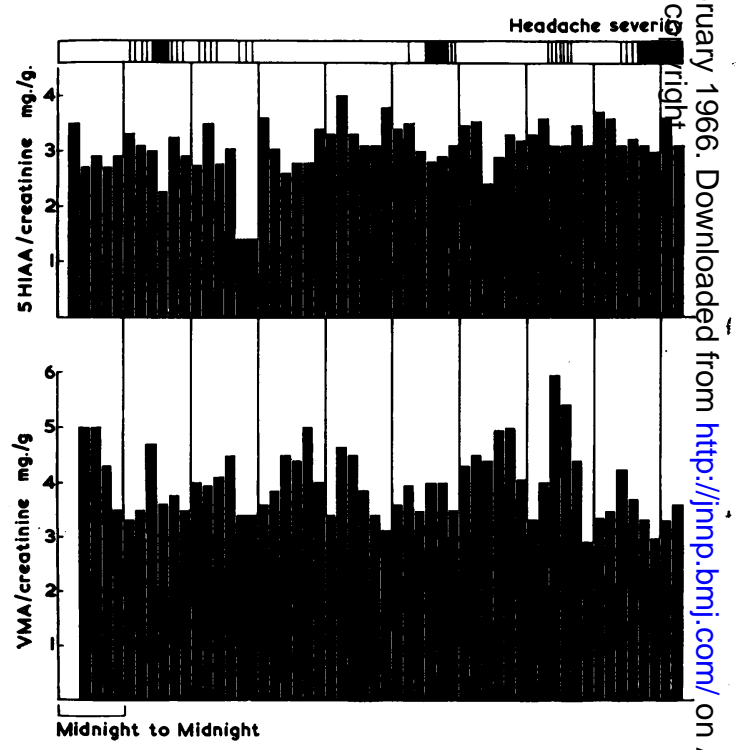

FIG. 2. Serial four-hourly urinary excretion of $5 H I A A$ S creatinine and V.M.A./creatinine by the migraine patien $H$.R. The severity and duration of headache is indicated as the top of the figure. $\square$, severe headache; ||l||, moderato headache. 


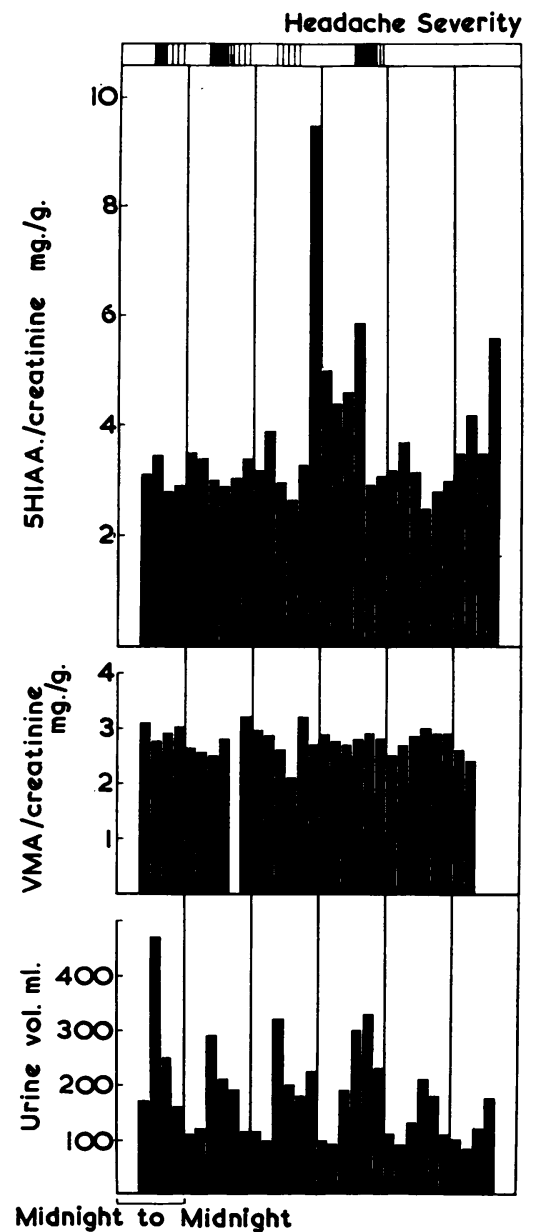

FIG. 3 .

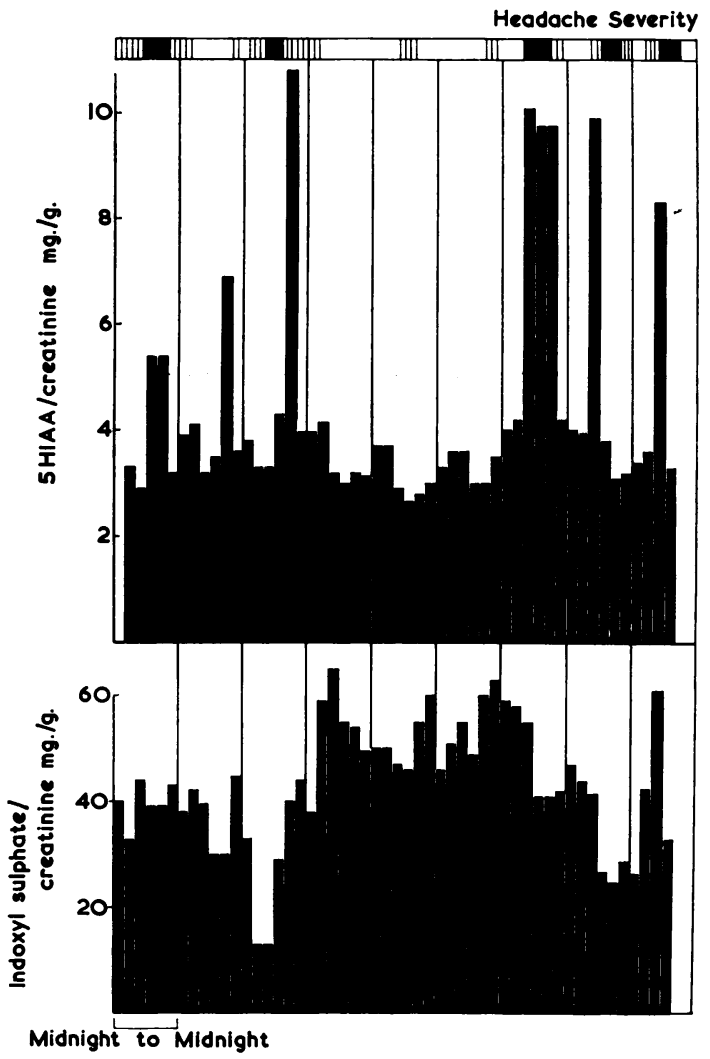

FIG. 4.

FIG. 3. Serial four-hourly urinary excretion of $5 H I A A / c r e a t i n i n e$, V.M.A./creatinine, and water by the migraine patient F.R. Headache is shown as in Figure 2.

FIG. 4. Serial four-hourly urinary excretion of $5 H I A A /$ creatinine and indoxyl sulphate/creatinine by the migraine patient $M . C r$. Headache is shown as in Figure 2.

This may be explained by a slight diurnal variation in creatinine excretion in the opposite direction which was observed, and is consistent with the somewhat higher creatinine excretion during the day than during the night reported by Bartter, Delea, and Halberg (1962).

Figure 3 shows the excretion pattern of F.R., a migrainous subject with high 5HIAA excretion for a 20-hour period towards the end of which a severe attack occurred. Two other severe attacks which occurred during the period of investigation were not associated with 5HIAA peaks. None of the attacks were associated with V.M.A. peaks. Diuresis occurred during the episodes of headache.

Figure 4 shows the pattern of a second migrainous subject, M.Cr. Here there is a strong suggestion of correlation between severe episodes of headache and 5HIAA peaks. Two periods of three days with severe headaches and 5HIAA peaks are separated by a period of three days with neither severe headaches nor 5HIAA peaks. Four out of five of the 5HIAA peaks are associated with or just precede the severe part of four out of the five severe episodes of headache. There is no reason to believe that the peaks are due to dietary effects. Known 5HIAA precursors were not included in the diet and there were no qualitative dietary differences between some of the peak days and non-peak days. Cigarette smoking has been reported by Schievelbein, Surberg, and Werle (1962) to affect 5HT metabolism and by Westfall and Watts (1964) to affect catecholamine metabolism. However, the patients H.R. and F.R. and M.Cr. did not smoke. The patient M.Cr. was studied over further periods of one week on a 
Complan diet and one week on ordinary hospital diet. Unfortunately, neither severe headaches nor 5HIAA peaks occurred during this period. During the period shown in Fig. 4 urinary indoxyl sulphate was also determined. It is of some interest that the excretion of this tryptophan metabolite, which is derived entirely from intestinal bacterial breakdown of tryptophan, was higher during the period in which the patient was free of severe headaches. Probably this is due to a somewhat higher dietary intake of tryptophan during the headache-free period, rather than to a diversion of tryptophan to the 5HT pathway in the headache period. The patient F.R. did not show any obvious relationship between 5HIAA and indoxyl sulphate excretion, although in this case the period of investigation was shorter and only one 5HIAA peak occurred. Some contributory evidence indicating the significance of the peaks of 5HIAA excretion in Figs. 3 and 4 is provided in Table II.

\section{TABLE II}

\begin{tabular}{|c|c|c|}
\hline \multicolumn{2}{|l|}{$\begin{array}{l}\text { Drug } \\
\text { (given orally) }\end{array}$} & $\begin{array}{l}\text { Percentage Change in } 5 \text { HIAA/Creatinine afte } \\
\text { Administration of Drug (comparing Periods os } \\
\text { Five Hours) }\end{array}$ \\
\hline $\begin{array}{l}\text { L.S.D. } \\
\text { Ergotamine } \\
\text { B.O.L. } \\
\text { Reserpine } \\
\text { Mescaline }\end{array}$ & $\begin{array}{l}(100 \mu \mathrm{gg}) \\
(250 \mu \mathrm{g}) \\
(250 \mu \mathrm{g}) \\
(2.5 \mathrm{mg} .) \\
(500 \mathrm{mg} .)\end{array}$ & $\begin{array}{l}-32,-29,-23,-14,-24 \\
-15,-13,-4,+18,+2,+3,-21,+37 \\
-23,+16,-33,-18,-16,-7 \\
-6,-16,+80,+11,+41 \\
+13,-21\end{array}$ \\
\hline Controls & & $-7,+25,-2,-27,+17,-8,-40$ \\
\hline
\end{tabular}

The results presented here were obtained some years ago in work not directly connected with the present study and on patients not under any dietary restriction. It is apparent that in no case was there evidence of a variability in 5HIAA excretion following drugs approaching that shown in Figs. 3 and 4, with the exception of one subject to whom reserpine was given. Also (not including this patient) the highest 5HIAA/creatinine content of any urine specimens referred to in Table II was 5.81 , which is about half of the 5HIAA/creatinine ratios at five of the peaks of Figures 3 and 4.

The patient H.R. showed some diurnal variation of V.M.A. excretion, averages of four-hour urine being 3.82 and $4.66 \mathrm{mg}$. V.M.A./g. creatinine between 8 p.m. and 8 a.m. and between 8 a.m. and 8 p.m. respectively on non-headache days. On headache days the variation was less, being 3.41 and 3.83. The patient F.R. showed no significant diurnal variation, excreting 2.67 and $2.80 \mathrm{mg}$. $/ \mathrm{g}$. on non-headache or mild headache days, 2.79 and $2.80 \mathrm{mg}$. $/ \mathrm{g}$. On severe headache days. The peak of 5HIAA excretion was not associated with elevated V.M.A. excretion. Excretion of V.M.A. by M.Cr. was also shown not to change significantly during an episode of severe headache in which a 5HIAA peak $Z$ occurred.

\section{DISCUSSION}

The finding by Sicuteri et al. (1961) that 5HIAAN excretion by certain migrainous patients is elevated ? in association with severe migraine attacks has been reinvestigated in a study in which particular atten $-\vec{z}$ tion was paid to the possibility of elevated 5HIAA excretion due to dietary precursors or to cigarette smoking, or to apparently high results due to? defective methodology. Only two out of nine $\overline{\bar{n}}$ migrainous subjects studied had significant urinary 5HIAA peaks, and, in one of these subjects, only a $\propto$. single 5HIAA peak was found. In the case of the single subject who showed a number of 5HIAA peaks, $\overrightarrow{0}$ these correlated well with the most severe episodes of headache as indicated by the subjective impressions $\vec{\omega}$ of the patient. Neither of the patients showing S 5HIAA peaks excreted as much 5HIAA during those periods as did the patients described by Sicuteri et al. (1961). Direct comparisons are impossible, however, as the size of the group of patients. studied by these workers was not reported. Also, o neither factors such as self-selection of patients n\&r응 their subsequent selection for study may be corig- pared. While the present work was being done, 7 a paper by Curran and Lance (1964) describing a을 clinical trial of methysergide appeared in whichoa rise of 5HIAA excretion together with a fall of blocd 5HT in migraine attacks is mentioned but in whr numerical data are not given.

The 5HIAA peaks may be due to the increased blood hydration which occurs in the prodromal and early stages of a migraine attack (Campbell, Hay, and Tonks, 1951). It has recently been shown that intravenous injection of isotonic glucose solution or physiological saline resulted in a marked rise of urinary 5HIAA in female volunteers (Bertaccinio and Baronio, 1965). On the other hand, it is possible 3 that the blood hydration is itself a result of liberation of 5HT as this substance has been shown to have: a marked antidiuretic effect (Erspamer and Bertaccini, 1962). Another possible factor involved mayo be gastrointestinal symptoms which are frequently윽 associated with migraine attacks. Bülbring and $\mathrm{Lin}$. (1958) find that not only is peristalsis increased byo intraluminal administration of 5HT but that intra- . luminal stimulation itself caused liberation of 5HT.. 잉 Also, Adams (1960) has reported that the administra- $\rightarrow$ tion of magnesium sulphate or carbachol results in elevated serum 5HT.

Possibly some of the frequent gastrointestinal and. vascular symptoms in migraine are mediated via ${ }^{N}$ 5HT release. Thus, amongst other effects, the in- N 
jection of 5HT in man results in nausea, abdominal cramp, increased peristaltic sounds, diarrhoea, and tingling in the extremities (Hendrix, Atkinson, Clifton, and Ingelfinger, 1957).

Ostfeld (1960) found that injection of 5 HT in the area of the superficial temporal artery induced mild headache in five migraine subjects and intravenous infusion of larger amounts induced headache in 11 out of 25 patients. In contrast Kimball, Friedman, and Vallejo (1960) failed to induce headache in similar experiments. Headache was also not induced by 5 -hydroxytryptophan (5HTP), the precursor of 5HT which, unlike the latter, penetrates readily into the brain. Also, migrainous headache has not been reported as a symptom of carcinoid disease in which enormous amounts of 5HT may be metabolized. Thus, probably the headache symptoms in migraine are not caused simply and directly by intermittent 5HT release. Reserpine, which depletes tissues of 5HT and other amines, was found by Kimball and Friedman (1961) to induce headache in migraine sufferers, while Nardil, which inhibits the breakdown of 5HT and other amines, caused decreased frequency and severity of headaches. This latter finding may perhaps, however, be a result of elevating the mood due to this antidepressant drug.

The opposite effects of reserpine and Nardil, the claim by Kimball and Friedman (1961) that 5HT injection alleviates spontaneous or reserpine-induced headaches, and also the finding of high urinary levels of 5HIAA in episodes of severe headache suggests that some migraine headaches may be due to depletion of 5HT from certain sites. Thus, elevation of 5HT either in carcinoid disease or following the injection of 5HT or 5HTP would not be expected to precipitate headache. No detailed biochemical studies have been made on reserpine headache. It would be of value to study the relationship between reserpine-provoked headache and the increase in urinary 5HIAA excretion due to reserpine.

Although Sicuteri (1963) has reported elevated excretion of V.M.A. during attacks of migraine, this was not observed in the present study. One patient exhibited diurnal variation of V.M.A. excretion, more being excreted during the day than during the night. This is in agreement with McDonald (1961) who found somewhat greater excretion during the day. On days with episodes of severe headache this subject showed less diurnal variation. This presumably relates to the decreased physical activity during severe attacks.

In conclusion, it must be stressed that an association between 5HIAA excretion and migraine attacks has only been shown in one subject. This may indicate the existence of a subgroup of migrainous subjects in whom abnormal 5HT metabolism is a fundamental factor in the disease. On the other hand, the primary disturbance in migraine may be in another area of metabolism and elevated 5HIAA excretion a secondary consequence which appears in some subjects.

\section{SUMMARY}

No significant variation of urinary excretion of 5hydroxyindolyl acetic acid was observed in seven of nine migrainous subjects. One subject intermittently excreted elevated amounts of 5-hydroxyindolyl acetic acid associated with episodes of severe headache. No correlation between 3-methoxy-4-hydroxymandelic acid excretion and headache was found. The possible significance of the high 5-hydroxyindolyl acetic acid excretion in migraine is discussed.

We thank Sandoz Ltd. for financial support and Dr. Macdonald Critchley for permission to study patients under his care

\section{REFERENCES}

Adams, B. (1960). Serum 5-hydroxytryptamine levels following experimental increase in gastrointestinal activity in man. Lancet, 1 , 207-208.

Bartter, F. C., Delea, C. S., and Halberg, F. (1962). A map of blood and urinary changes related to circadian variations in adrenal cortical function in normal subjects. Ann. N.Y. Acad. Sci., 98, 969-983.

Bertaccini, G., and Baronio, G. (1965). Urinary excretion of 5hydroxyindoleacetic acid after administration of fluid in man. Arch. int. Pharmacodyn., 155, 57-62.

Bruce, D. W. (1960). Serotonin in pineapple. Nature (Lond.), 188, 147.

Bülbring, E., and Lin, R. C. Y. (1958). The effect of intraluminal application of 5-hydroxytryptamine and 5-hydroxytryptophan on peristalsis; the local production of 5-HT and its release in relation to intraluminal pressure and propulsive activity. J. Physiol. (Lond.), 140, 381-407.

Campbell, D. A., Hay, K. M., and Tonks, E. M. (1951). An investigation of the salt and water balance in migraine. Brit. med. J., 2, 1424-1429.

Curran, D. A., and Lance, J. W. (1964). Clinical trial of methysergide and other preparations in the management of migraine. $J$ Neurol. Neurosurg. Psychiat., 27, 463-469.

Curzon, G., and Walsh, J. (1962). A method for the determination of urinary indoxyl sulphate (indican). Clin. Chim. Acta, 7, 657663.

Degkwitz, R., Frowein, R., Kirberger, E., Kulenkampff, C., and Mohs, U. (1962). Uber Normalwerte der stündlichen 5HIES-Ausschiedung im Urin beim Menschen und die Messungen störende Faktoren. Klin. Wschr., 40, 285-289.

Erspamer, V., and Bertaccini, G. (1962). Observations on the antidiuretic action and the fate of 5-hydroxy-DL-tryptophan in the rate organism. Arch. int. Pharmacodyn., 137, 6-23.

Hendrix, T. R., Atkinson, M., Clifton, J. A., and Ingelfinger, F. (1957). The effect of 5-hydroxytryptamine on intestinal motor function in man. Amer. J. Med., 23, 886-893.

Jepson, J. B. (1955). Paper chromatography of urinary indoles. Lancet, 2, 1009-1011.

Kimball, R. W., and Friedman, A. P. (1961). Studies on the pathogenesis of migraine. In Recent Advances in Biological Psychiatry, ed. J. Wortis, 3, 200-206. Grune and Stratton, New York. - and Vallejo, E. (1960). Effect of serotonin in migraine patients. Neurology (Minneap.), 10, 107-111. 
King, E. J., and Wootton, I. D. P. (1964). Micro-analysis in Medical Biochemistry, p. 174. Churchill, London.

Kirberger, E., and Braun, L. (1961). Uber das Vorkommen von 5Hydroxytryptamin in der Walnuss (Juglans regia). Biochim. biophys. Acta (Amst.), 49, 391-393.

Marcussen, R. M., and Wolff, H. G. (1950). Studies on headache. Arch. Neurol. (Chic.), 63, 42-51.

McDonald, R. (1961). Discussion on biochemical mechanisms related to the site of action of psychotropic drugs. Neuropsychopharmacology, 2, 445-448.

Ostfeld, A. M. (1960). Migraine headache. Its physiology and biochemistry. J. Amer. med. Ass., 174, 1188-1190.

Pisano, J. J., Crout, J. R., and Abraham, D. (1962). Determination of 3-methoxy-4-hydroxymandelic acid in urine. Clin. chim. Acta, 7, 285-291.

- Oates, J. A., Karmen, A., Sjoerdsma, A., and Udenfriend, S. (1961). Identification of $p$-hydroxy- $\alpha$-(methylaminomethyl) benzyl alcohol (synephrine) in human urine. J. biol. Chem., 236, 898-901.

Rosenfeld, G. (1960). Inhibitory influence of ethanol on serotonin metabolism. Proc. Soc. exp. Biol. (N.Y.), 103, 144-149.
Schievelbein, H., Surberg, U., and Werle, E. (1962). Erhöhung der Ausscheidung von 5-Hydroxyindolessigsäure bei Rauchern.(D Klin. Wschr., 40, 52-53.

Sicuteri, F. (1963). Prophylactic treatment of migraine by means of lysergic acid derivatives. Triangle (En.), 6, 116-125.

—, Fanciullacci, M., Del Bianco, P. L., and Franchi, G. (1964) Inibizione della venocostrizione da 5 -idrossitriptamina nell, uomo da parte del metisergide (UML-491) e di altri antisero- $T$ toninici. Boll. Soc. ital. Biol. sper., 40, 1151-1152.

$\longrightarrow$ Testi, A., and Anselmi, B. (1961). Biochemical investigations in $\widehat{\Upsilon}$ headache: increase in the hydroxyindoleacetic acid excretion $\overline{0}$ during migraine attacks. Int. Arch. Allergy, 19, 55-58.

Todrick, A., Dick, M., and Tait, A. C. (1958). Effect of reserpine in therapeutic dosage on excretion of 5-hydroxyindoleacetic acid. Brit. med. J., 1, 496-499.

Waalkes, T. P., Sjoerdsma, A., Creveling, C. R., Weissbach, H., and Udenfriend, S. (1958). Serotonin, norepinephrine, and related $\bar{C}$ compounds in bananas. Science, 127, 648-650.

West, G. B. (1958). Tryptamines in edible fruits. J. Pharm. Pharmacol., 10, 589-590.

Westfall, T. C. and Watts, D. T. (1964). Catecholamine excretion in $\vec{D}$ smokers and non-smokers. J. appl. Physiol., 19, 40-42. 